\title{
TOWARDS DEVELOPING A WEB-BASED GAP MANAGEMENT INFORMATION SYSTEM FOR CUCUMBER IN CHINA
}

\author{
Jianping Qian ${ }^{1}$, Ming Li $^{2}$, Xinting Yang ${ }^{1, *}$, Xuexin Liu ${ }^{1}$, Jihua Wang ${ }^{1}$ \\ ${ }^{1}$ National Engineering Research Center for Information Technology in Agriculture Beijing, \\ 100097, P. R. China \\ ${ }^{2}$ College of Information and Electrical Engineering China Agricultural University Beijing, \\ 100083, P. R. China \\ "Corresponding author. Room 307, Beijing Agricultural Science Mansion, Building A, Banjing, \\ Haidian district, Beijing, 100097, P. R. China, Tel: +86-10-51503476; Fax: +86-10 -51503476; \\ Email address: yangxt@nercita.org.cn
}

Abstract: The integrated management of Good Agricultural Practices (GAP) for cucumber (Cucumis sativus L.) plays a key role in guaranteeing the high quality and safety of cucumber production. This paper describes an attempt to develop a web-based GAP management information system for cucumber. Through applying the system methodology and mathematical modeling technique to analyzing the dynamic relationships between control point of GAP and produce process of cucumber, self-assessments algorithm was established. Based on the algorithm, Web-based GAP management information system for cucumber (Cucumber-GAPS) with the functions of data manage, criterion query, GAP self-check, model manage and so on was designed with the web structure of Browse/Server, and it has been applied successfully in China.

Keywords: cucumber; Good Agricultural Practices (GAP); self assessment; management information system

\section{INTRODUCTION}

With the requirement and emphasis on quality, safety and sustainability of farm produce, it has been placed new demands for the development and adoption of Quality Assurance Systems, such as Good Agricultural Practices

Qian, J., Li, M., Yang, X., Liu, X. and Wang, J., 2008, in IFIP International Federation for Information Processing, Volume 259; Computer and Computing Technologies in Agriculture, Vol. 2; Daoliang Li; (Boston: Springer), pp. 1205-1212. 
(GAP) (Linus, 2003). GAP are defined as general practices to reduce microbial food safety hazards in the cultivation, harvesting, sorting, packing and storage operations for fresh fruits and vegetables, and should be developed in a stepwise manner based on the risk associated with individual fruits and vegetables and the scientific data available (De Roever, 1998; Pabrua, 1999). Countries over the world are recognizing its importance (Adriano et al, 2006). The Euro_Retailer Produce Working Group and Good Agricultural Practices (EUREPGAP) started as an initiative of the retailers in 1997 to harmonize GAP for all sources of supply; According to the Food and Drug Administration (FDA), GAP was an offshoot of the Food Safety Initiative/Action plan developed in 1998 (Howard and Gonalez, 2001).

In China, the Agro-Food Safety Program which is basically a guarantee system on standards, monitoring and certification was implemented in 2001. This program also controls measures for inputs and environmental protection. China's Good Agricultural Practices (CHINAGAP) was established in December 2005 and enforced in May 2006 (Wu and Liang, 2007). It includes 11 standards such as Terminology, all farm base control points and compliance criteria, crops base control points and compliance criteria, combinable crops control points and compliance criteria, fruit and vegetable control points and compliance criteria and so on (GB/T 20014.1-20014.112005).

Relative information systems serving for GAP are few according to literature review. Based on the principle of export vegetable safety production process controlling, Hazard Analyses Critical Control Points (HACCP) and Good Manufacturing Practice (GMP), the development of Intelligent Decision Support System for Export Vegetable Safety Production based on HACCP was reported (Shen and Huang 2005). The lack of such information represents a gap in our knowledge of GAP information systems, thus a web-based CHINAGAP Management Information System for Cucumbers in China has been designed.

\section{ANALYSIS OF CUCUMBER PRODUCE PROCESS BASED ON GAP}

GAP, are recommended, in order to sustain best practices for farming, i.e. soil and water management, crop production, storage, waste disposal etc. China has moved to benchmark national Good Agricultural Practices (CHINAGAP) with EUREPGAP (Nigel and Elmé, 2005). From figure 1, the cucumber produce process based on CHINAGAP included eight sections or blocks: (1) seed and nursery, (2) site selection, (3) crop production, (4) harvest and transport, (5) storage, washing and treatment, (6) environment, 
waste $\&$ pollution, operator health, safety \& welfare, (7) documentation, traceability and quality system requirements, (8) general regulations.

Figure 1 shows the total produce process of cucumber is covered. The first linked to the farm in which the crop is grown, until the moment when the crop is harvested, after which the recording is linked to batches or lots and the produce handling site. The General Regulation which sets out the rules by which the standard will be administered. Control Points and Compliance Criteria Protocol (CPCC) including in (1)-(7) is the standard with which the farmer must comply, and which gives specific details on how the farmer complies with each of the scheme requirements.

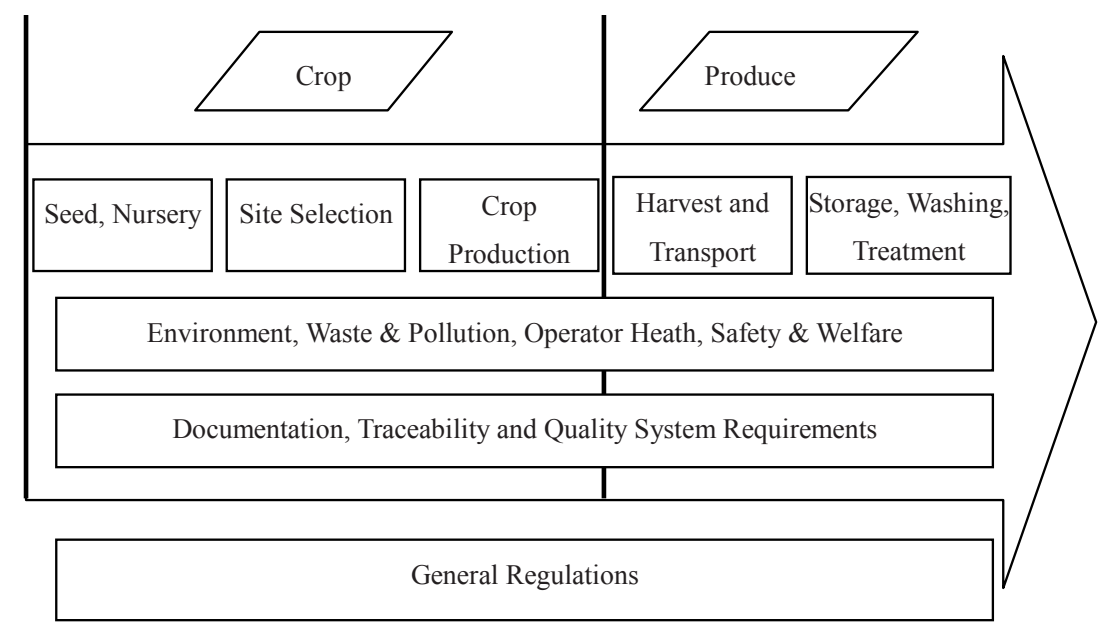

Fig. 1. Produce process based on CHINAGAP for cucumber

\section{ESTABLISHMENT SELF-ASSESSMENTS ALGORITHM}

The checklist used for inspection of producers, which contains all the control points and must be used during inspection by the Certification Bodies (CB). The checklist can also be used by the producer/group when performing the self-assessments.

Compliance with CHINAGAP Fruit and Vegetables consists of three types of control points, that the applicant is required to undertake in order to obtain CHINAGAP recognition; Grade 1 (MAJOR MUSTS). Grade 2 (MINOR MUSTS) and Grade 3 (RECOMMENDATIONS), and must be fulfilled as follow Fig. 2. 


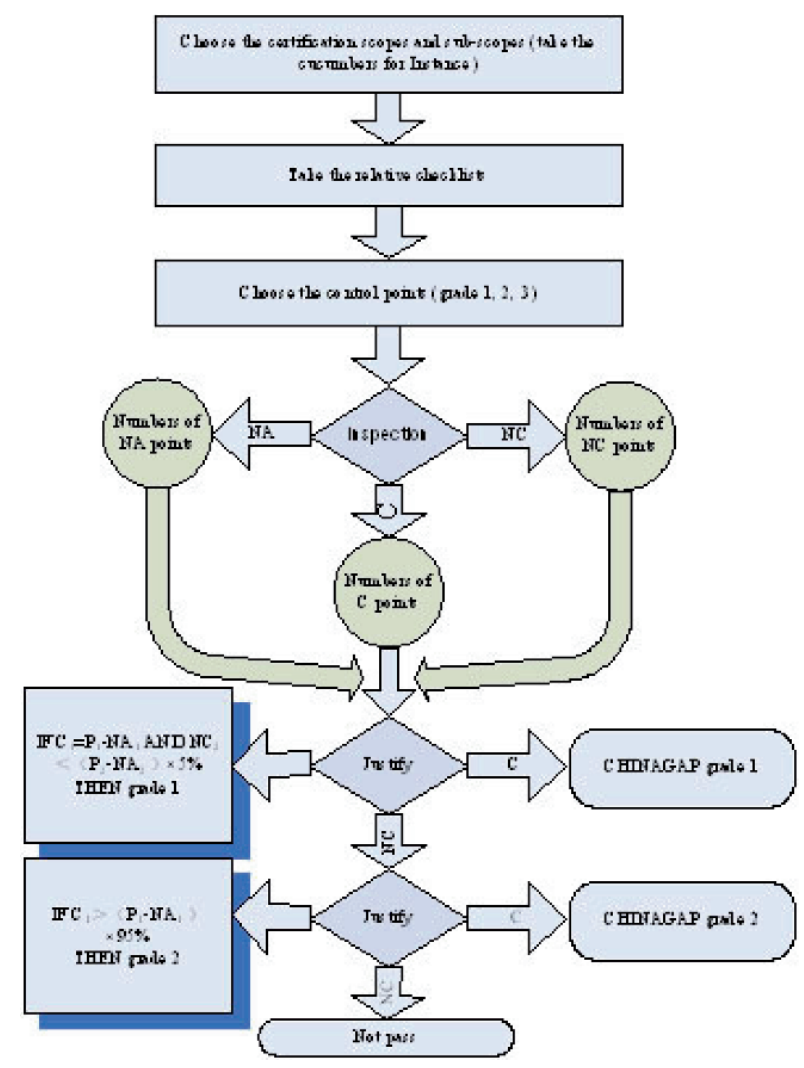

Fig. 2. CHINAGAP self assessment flow

NA: Not Applicable; NC: Not Compliance; C: Compliance

\section{SYSTEM DESIGN}

\subsection{System Architecture}

GAP Management Information System for Cucumber is composed of four layers: user browse layer, service layer, .Net framework and base layer (Fig. 3). The first layer is a standard browser, such as Internet Explorer or Netscape, can transfer request to business service layer, receive and analyze $\mathrm{html}$ document from server. The second layer is web server with Microsoft Internet Information Server 6.0. The third layer consists of business facade layer and business rules layer. The business façade layer is the separate layer which insulates user interface and varied business and the business rules layer includes login, data access and so on. The fourth layer consists of database layer, standard base and model layer including environment 
evaluation model, early warning model of cucumber disease, balanced fertilization model and self-assessments model.

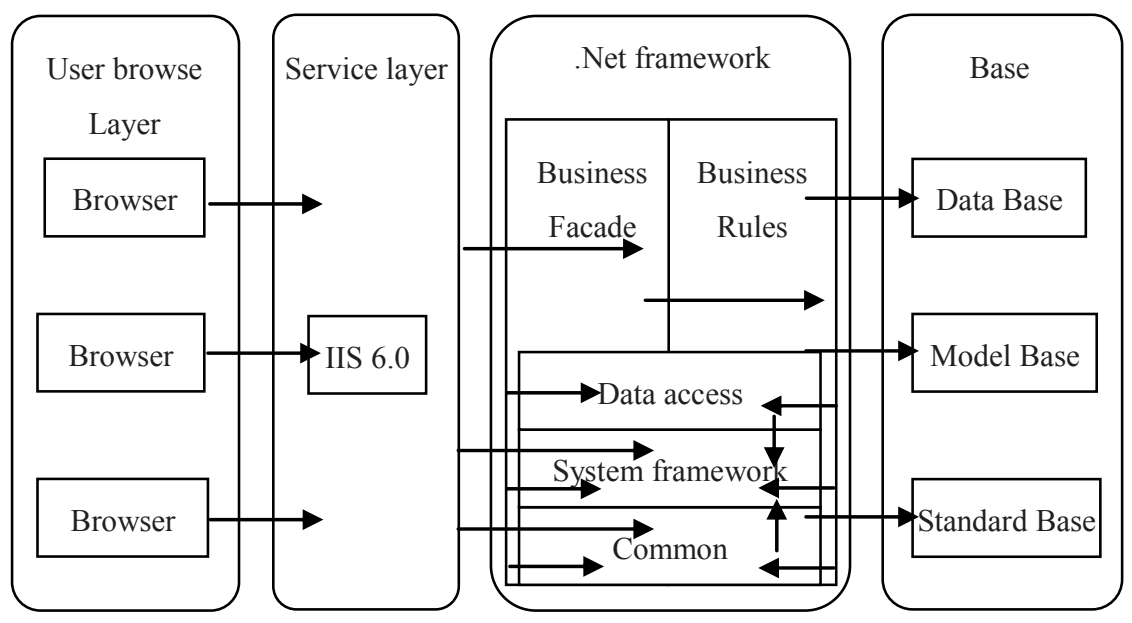

Fig. 3. Architecture of cucumber-GAPS

\subsection{System Function}

The system architecture (Fig. 4) is described below.

\section{System Setting}

Two functions of base setting and user setting is included. The former indicates enterprise basal information setting, data server address setting and so on. The latter indicates user information addition, user information edition and purview distribution.

\section{Data Manage}

Data import, data export, data upload and data download is provided in the system. The data of excel format and access format can be import and export. Data upload and download between server and customer is by web service.

\section{Criterion Query}

Criterion query consists of control point query including different phase of seed, plant, fertilize, plant prevent and standard query including Freepollution Products, Green-Food and Organic-Food standard. Two query matters which are singleness query and assorted query are provided. When user inputs the query condition, the query result is showed. 


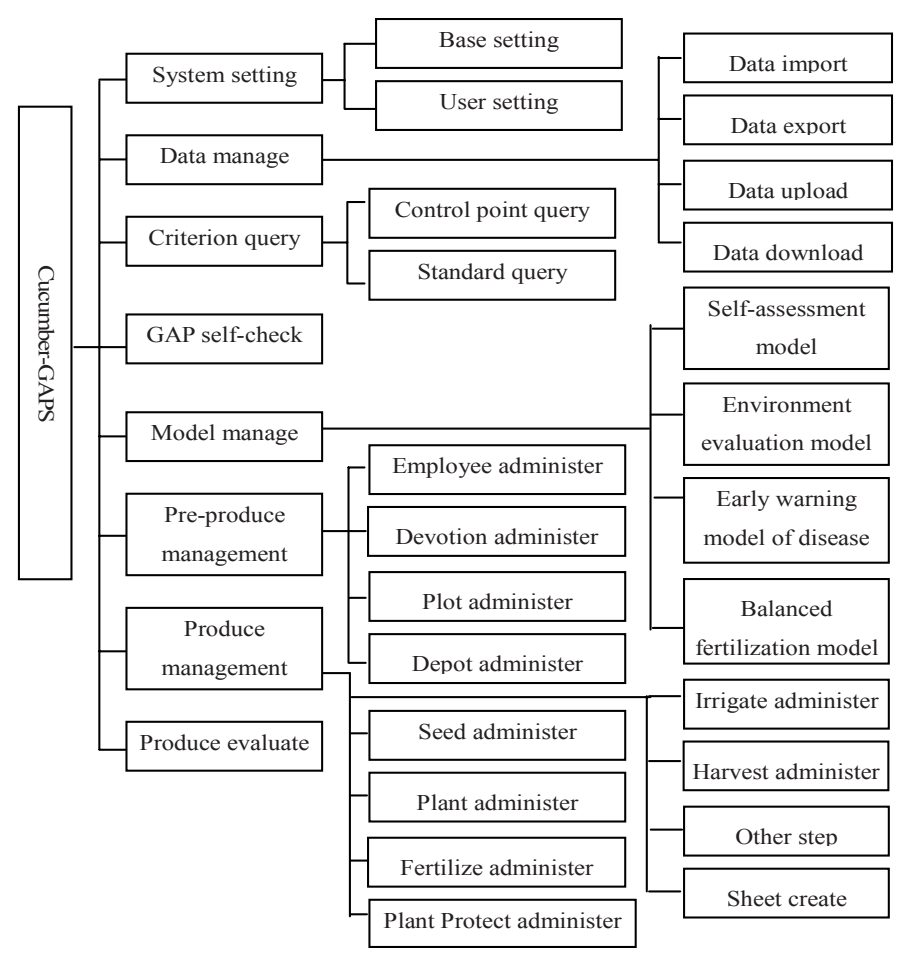

Fig. 4. Function of cucumber GAPS

\section{GAP Self-check}

The result whether the enterprise is accord with the criterion of GAP can be indicated according to self-check with GAP Management Information System for Cucumber. A check-list containing 95 questions attributed three grades was drawn up according to Good Agricultural practice (GB/T 20014.1-20014.11) and, distributed in ten sections or blocks: (1) varieties and rootstocks, (2) site history and site management, (3) soil and substrate management, (4) fertilizer use, (5) irrigation, (6) crop protection, (7) harvesting, (8) produce handling, (9) worker welfare and (10) environmental issues.

\section{Model Manage}

Four kinds of model are managed in the system. Self-assessment model is established on basis of self-assessment algorithm, and other models are based on the theory of risk analysis (Jacob, 2006). The system provided the management of risk assessment, risk management and risk communication. 


\section{Pre-produce Management}

Employees administer, devotion administer, Plot administer and depot administer are provided in the system. The information of employee is added, delete and edit in the part of employee administer. The information of source, specification, amount and purchaser about seed, pesticide and fertilizer is managed in the part of devotion administer.

\section{Produce Management}

The crucial control points including seed, plant, fertilize, irrigation, plants protect and harvest are selected and supervised according to GAP in the system. For example, in harvest administer, when the date of harvest is input to the system, the hint whether exceeds the safety interval schedule is showed. The producer can adjust the date of harvest in order to produce safety farm products according to the hint. The function of GAP form table print is provided in this part.

\section{Produce Evaluate}

Executive conditions of varied control point are evaluated via comparing actual produce records with GAP criterions. Improved measures are afforded for the sake of advance the produce safety.

\section{CONCLUSION}

GAP is used widely as a management tool for ensuring farm produce safety, but an exercisable software system for GAP is reported rarely. In this paper, by applying the system methodology and mathematical modeling technique to analyzing the dynamic relationships between control point of GAP and produce process of cucumber, self-assessments algorithm was established. Based on the algorithm, Cucumber-GAPS with the functions of data manage, criterion query, GAP Self-check, model manage and so on were designed with the web structure of Browse/Server.

\section{ACKNOWLEDGEMENTS}

It is an outcome of Hi-Tech Research and Development Program of China (No: 20060110Z2002) and National Key Technology R\&D Program (No: 2006BAD10A08). 


\section{REFERENCES}

Adriano G C, Sergio A C, Maria C A. Good agricultural practices in a Brazilian produces plant. Food Control, 2006, 17: 781-788

De R C. Microbiological safety evaluations and recommendations on fresh produce. Food Control, 1998, 9: 321-347

GB/T 20014. 1-20014.11-2005. Good agricultural practice (in Chinese)

Howard L R, Gonzalez A R. Food safety and produce operation: what is the future? Hortscience, 2001, 36: 33-39

Jacob M. Risk analysis-an essential modern approach to food safety. Environmental Policy and Practice, 1996, 6: 91-96

Linus U O. Traceability in agriculture and food supply chain: a review of basic concepts, technological implications, and future prospects. Food, Agriculture \& Environment, 2003, $1.1(1): 101-106$

Nigel G, Elmé C. Options for the development of National/Sub-regional Codes of Good Agricultural Practice for Horticultural Products Benchmarked to EuropGAP. Http://www.unctad.org/trade_env/test1/meetings/eurepgap/EurepGAP_benchmarking_UN CTAD_November-NG.pdf. September 2005

Pabrua F. Good agricultural practices: methods to minimize microbial risks. Diary, Food and Environmental Sanitation, 1999, 19(7): 523-526

Shen G R, Huang D F. Intelligent decision support system of export vegetable safety production based on HACCP. Agriculture Network Information, 2005, 11:18-20 (in Chinese with English abstract)

Wu R, Liang Y. GAP management system and software development for Chinese Crude Drugs. Beijing: Chinese Medical and Pharmaceutical Science Press. 2007, p. 29 (in Chinese) 